\title{
A morphometric approach to the specific separation of the humeri and femora of Dicraeosaurus from the Late Jurassic of Tendaguru, Tanzania
}

Daniela Schwarz-Wings and Nico Böhm

Acta Palaeontologica Polonica 59 (1), 2014: 81-98 doi: http://dx.doi.org/10.4202/app.2011.0095

The two species of dicraeosaurid dinosaurs Dicraeosaurus, Dicraeosaurus hansemanni, and Dicraeosaurus sattleri, have been distinguished mainly by their differences in size and geological age, as they occur in different members of the Late Jurassic Tendaguru Formation of Tanzania. Linear and geometric morphometric measurements distinguish between the humeri and femora of both species. Linear measurements and Principal Component Analysis of Thin-plate Splines reveal strong differences in size and shape between their humeri and weak differences between their femora, also supported by a Discriminant Factor Analysis. Generally, the humerus and femur of D. hansemanni are slightly longer and more robust than those of $D$. sattleri. Further, the humerus is shorter in relation to the femur in $D$. sattleri, related to its more distally positioned deltopectoral crest, resulting in differences in its arc of movement and mechanical power. Thus, a morphological separation between the humeri and femora of D. hansemanni from the Middle Dinosaur Member and D. sattleri from the Upper Dinosaur Member of the Tendaguru Formation can be confirmed. Morphometric comparisons of the humeri and femora of Dicraeosaurus with the single known humerus and femur of Amargasaurus cazaui reveal many shape differences between the two genera, which are especially well marked in the Thin-plate Splines analysis and affect in particular the humerus. These results suggest a closer relationship between $D$. hansemanni and $D$. sattleri than between $D$. sattleri and A. cazaui, and a clear separation between the two genera.

Key words: Dinosauria, Sauropodomorpha, Dicraeosaurus, Amargasaurus, morphometry, taxonomy, statistic, humerus, femur, Jurassic, Tendaguru, Tanzania.

Daniela Schwarz-Wings [d.schwarz-wings@mfn-berlin.de]and Nico Böhm [nico.boehm@cms.hu-berlin.de], Museum für Naturkunde Berlin, Invalidenstraße 43, D-10115 Berlin, Germany. 
This is an open-access article distributed under the terms of the Creative Commons

Attribution License (for details please see creativecommons.org), which permits unrestricted use, distribution, and reproduction in any medium, provided the original author and source are credited.

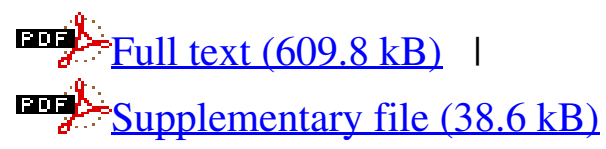

